\title{
O software Geogebra e a pipa: possibilidades pedagógicas para o ensino de
}

\section{Geometria Plana}

\author{
The Geogebra software and the pipa: pedagogical possibilities for teaching Plane Geometry \\ El software Geogebra y la cometa: posibilidades pedagógicas para la enseñanza de la Geometría
}

\section{Resumo}

Este estudo é fruto das reflexões decorrentes da prática de um Projeto de Intervenção Pedagógica realizado com alunos do $8^{\circ}$ ano do Ensino Fundamental de um Colégio Estadual no interior do estado do Paraná. Expõe as contribuições e potencialidades de um software de Geometria Dinâmica - GeoGebra - e de conceitos matemáticos existentes na construção de uma pipa para o ensino de tópicos de Geometria Plana. O objetivo estabelecido foi o de investigar de que forma o uso do software GeoGebra e a confecção de pipas podem contribuir para o ensino de tópicos de Geometria Plana para alunos do $8^{\circ}$ ano do Ensino Fundamental. O uso dessa prática pedagógica auxilia na construção dos conhecimentos supracitados, à medida que coloca o aluno em uma posição dinâmica, de autonomia, ao investigar as propriedades do conteúdo em questão. Como aporte teórico foram utilizados estudos de Soares (2008), Bona (2009), Ramalho (2013), Pereira (2010), entre outros. Por meio dessa atividade pedagógica, foi possível observar as potencialidades do ensino da Matemática por meio do software GeoGebra, ampliando as possibilidades metodológicas do professor. Por meio de um questionário aplicado ao final das atividades, os participantes puderam apresentar suas impressões sobre a aula. Os dados obtidos demonstraram que a utilização da pipa e do programa supramencionado enriquecem as aulas, auxiliam o processo de ensino e favorecem a integração entre os conteúdos de matemática, as novas tecnologias e o cotidiano dos alunos.

Palavras-chave: Geometria plana; GeoGebra; Pipa.

\begin{abstract}
This study is the result of reflections resulting from the practice of a Pedagogical Intervention Project carried out with students of the 8th year of elementary school of a State College in a town of the State of Paraná. It exposes the contributions and potentialities of a Dynamic Geometry software - GeoGebra - and mathematical concepts existing in the construction of the kite for the teaching of flat geometry topics. The objective was to investigate how the use of GeoGebra software and the making of kites can contribute to the teaching of Flat Geometry topics for 8th grade elementary school students. The use of this pedagogical practice helps in the construction of the aforementioned knowledge, as it places the student in a dynamic position of autonomy, when investigating the properties of the content in question. As theoretical contribution were used studies by Soares (2008), Bona (2009), Ramalho (2013), Pereira (2010), among others. Through this pedagogical activity it was possible to observe the potentialities of mathematics teaching through the GeoGebra software, which expands the methodological possibilities of the teacher. Through a questionnaire applied at the end of the activities, the participants were able to present their impressions about the class. The data obtained showed that the use of kite and the above-mentioned program enrich mathematics classes, help the teaching process and favor the integration between mathematics content and new technologies and students' daily lives.
\end{abstract}

Keywords: Flat geometry; GeoGebra; Kite.

\section{Resumen}

Este estudio es el resultado de reflexiones surgidas de la práctica de un Proyecto de Intervención Pedagógica llevado a cabo con estudiantes de $8^{\circ}$ grado de la escuela primaria de un Colegio del Estado en el interior del Estado de Paraná. Expone las contribuciones y el potencial de un software de Geometría Dinámica - GeoGebra - y de los conceptos matemáticos existentes en la construcción de la cometa para la enseñanza de temas de geometría plana. El objetivo 
establecido fue investigar cómo el uso del software GeoGebra y la confección de cometas pueden contribuir a la enseñanza de los temas de Geometría Plana para estudiantes de $8^{\circ}$ año de primaria. El uso de esta práctica pedagógica ayuda en la construcción de los conocimientos antes mencionados, ya que coloca al alumno en una posición dinámica, de autonomía, a la hora de investigar las propiedades del contenido en cuestión. Como soporte teórico se utilizaron los estudios de Soares (2008), Bona (2009), Ramalho (2013), Pereira (2010), entre otros. A través de esta actividad pedagógica, se pudo observar el potencial de la enseñanza de las Matemáticas a través del software GeoGebra, que amplía las posibilidades metodológicas del docente. A través de un cuestionario aplicado al final de las actividades, los participantes pudieron presentar sus impresiones de la clase. Los datos obtenidos mostraron que el uso de la cometa y el programa mencionado enriquecen las clases de Matemáticas, facilitan el proceso de enseñanza y favorecen la integración entre los contenidos de las matemáticas y las nuevas tecnologías y la vida cotidiana de los estudiantes.

Palabras clave: Geometria plana; GeoGebra; Cometa.

\section{Introdução}

Os conceitos geométricos permeiam nossa vida e podem ser encontrados em múltiplos contextos, como em embalagens de produtos disponíveis nas prateleiras do supermercado, em construções arquitetônicas e mesmo em elementos da natureza e do corpo humano. Podemos, ainda, encontrar geometria em momentos de diversão e objetos de entretenimento, como é o caso da pipa. Deste modo, o estudo da Geometria é fundamental na formação dos estudantes, pois auxilia na compreensão das situações do mundo, desenvolve o raciocínio lógico e proporciona um melhor entendimento de outras áreas do conhecimento. Essas discussões estão previstas na LDB (Lei de Diretrizes e Bases da Educação Nacional), nos PCNs (Parâmetros Curriculares Nacionais) e evidenciadas pela BNCC (Base Nacional Comum Curricular). Outrossim, pesquisadores da área da Educação Matemática também recomendam que os professores proporcionem aos alunos um ensino metodologicamente diferenciado, incluindo a utilização dos recursos tecnológicos, visando à compreensão e à interação dos conteúdos matemáticos com o mundo em que vivem. Nesse sentido, D’Ambrósio (2013, p. 32) defende que “ao se deparar com situações novas, reunimos experiências de situações anteriores, adaptando-as às novas circunstâncias e, assim, incorporando à memória novos fazeres e saberes".

As tecnologias da informação e comunicação estão em constante movimento e evolução, e, diante dessa nova realidade, faz-se necessário um novo modelo de escola. Costa e Fiorentini (2007) ressaltam que é necessário um novo trabalho docente no ensino, isto é, a introdução da tecnologia da informação e comunicação no meio escolar.

Parte importante do trabalho do professor na condução do processo de ensino é a proposição de situações que levem o aluno a refletir e reconhecer a matemática em situações do cotidiano, ao invés de rotinas memorizadas de resolução de algoritmos. Estas situações, por sua vez, podem ser realizadas através da utilização das novas tecnologias, em especial, o uso dos softwares Educativos.

Diante do exposto, cabe ao professor utilizar, de forma efetiva, as tecnologias existentes no exercício da profissão docente. Ao organizar e planejar suas ações, o uso de softwares educacionais pode auxiliar no processo de ensino, favorece a integração entre os conteúdos de matemática, as novas tecnologias e o cotidiano dos alunos. Segundo Miranda e Blaudares (2007),

A sociedade e a tecnologia estão integradas e a tecnologia tornou-se o aspecto dominante da civilização. A matemática é o sustentáculo lógico do processamento da informação, e o pensamento matemático é também a base para as atuais aplicações da tecnologia da informação. (Miranda \& Blaudares, 2007, p.73).

Nesse sentido, para essa proposta, foi escolhido o software de geometria dinâmica - GeoGebra. Acredita-se que a variedade de recursos disponibilizados permite que o aluno, através das suas manipulações, construa os conceitos matemáticos que se tornariam muito abstratos caso fossem trabalhados somente com o lápis e papel. Com a sua utilização é possível tornar o ensino da Matemática mais dinâmico, através das possibilidades de interação, dando condições de movimento ao que foi 
construído, estimula-o aluno a questionar, prever situações, formular hipóteses, fazer análises e experimentar.

O objeto dessa investigação, a qual versa sobre o Ensino de Geometria e Tecnologias por meio do uso de softwares educativos como facilitadores no processo de ensino de Geometria, é recorrente e de interesse na área educacional da Matemática. Assim, pode-se traduzir esse estudo no seguinte questionamento: De que forma o uso do software GeoGebra e a confecção de pipas pode contribuir para o ensino de tópicos de Geometria Plana para alunos do $8^{\circ}$ ano do Ensino Fundamental? Por assim ser, pretendeu-se investigar a utilização do software GeoGebra e como suas ferramentas auxiliam metodologicamente no Ensino de Geometria Plana.

Consonante ao exposto acima, essa proposta foi desenvolvida com alunos do $8^{\circ}$ ano do Ensino Fundamental, de forma presencial, em um colégio na cidade de Jacarezinho - PR. Foram propostas situações desafiadoras aos alunos, levando-os a formularem hipóteses e realizar simulações, de modo que fossem capazes de perceber a matemática presente na pipa e sua construção, bem como propiciar as trocas de ideias em grupos, tornando a Matemática mais atrativa e mais próxima do cotidiano vivenciado pelos participantes dessa pesquisa.

Almeja-se que o presente estudo possa contribuir com o ensino de conceitos de geometria, colocando professor e aluno em uma posição dinâmica e ativa frente às situações apresentadas, estimulando a autonomia dos discentes ao investigar propriedades matemáticas, de modo a levá-los a compreender o mundo de forma mais crítica.

\section{Pressupostos Teóricos}

Um grande desafio para os professores de Matemática é tornar as aulas mais atrativas, fazer com que os alunos compreendam a importância dessa disciplina e busquem conhecê-la. Observar o cotidiano em que o aluno está inserido pode contribuir com a prática docente, tornando a matemática perceptível em situações vivenciadas no dia a dia.

Segundo os Parâmetros Curriculares Nacionais - PCNs (1999, p.37), o objetivo geral da disciplina de Matemática é reconhecer os conhecimentos matemáticos como meio para compreender e transformar o mundo, bem como perceber o caráter de jogo intelectual, característicos da matemática, como aspecto que estimula o interesse, a curiosidade, o espírito de investigação e o desenvolvimento das capacidades para resolver problemas.

Dentre os conceitos matemáticos, temos o da Geometria, de extrema importância para o desenvolvimento das potencialidades cognitivas do aluno, corroborando para o raciocínio lógico e servindo como forma de prepará-lo para atuar convenientemente na sociedade em que vive. O ensino de Geometria, segundo Oliva (1981, p. 28), "é uma das áreas mais antigas de estudos e surgiu da necessidade dos povos de medir terras, construir moradias, templos, monumentos, etc".

Não se pode permitir que esses conceitos sejam ignorados, pois, conforme Miguel (1986, p. 66), “a Geometria é tão importante para a humanidade, que é inconcebível não a estudar na escola, pois o mundo em que vivemos é quase espontaneamente geométrico" (apud ECCO, 2016, p.15).

É importante, também, observar como a Geometria é vista nos documentos educacionais. A Base Nacional Comum Curricular (BNCC) aponta que:

A Geometria envolve o estudo de um amplo conjunto de conceitos e procedimentos necessários para resolver problemas do mundo físico e de diferentes áreas do conhecimento. Assim, nessa unidade temática, estudar posição e deslocamentos no espaço, formas e relações entre elementos de figuras planas e espaciais pode desenvolver o pensamento geométrico dos alunos. Esse pensamento é necessário para investigar propriedades, fazer conjecturas e produzir argumentos geométricos convincentes (Brasil, 2017, p.269)

Nesse sentido, é importante entender como os alunos interpretam situações envolvendo representações geométricas não só na sala de aula, mas em todo o nosso cotidiano. Lorenzato (1995, p.5) aponta que: 
[...] sem estudar Geometria as pessoas não desenvolvem o pensar geométrico ou o raciocínio visual e, sem habilidade, dificilmente conseguirão resolver as situações da vida que forem geometrizadas; também não poderão utilizar da Geometria como a fator altamente facilitador para a compreensão e resolução de questões de outras áreas de conhecimento humano. Sem conhecer a Geometria a leitura interpretativa do mundo torna-se incompleta, a comunicação das ideias fica reduzidas e a visão da Matemática torna-se incompleta" (Lorenzato, 1995, p. 5).

Segundo Silva (2011, p. 23), o ensino de Geometria, em muitos casos, é apresentado como uma abordagem baseada em um conjunto de definições, propriedades e fórmulas, desconectado de quaisquer aplicações de natureza histórica, lógica ou cotidiana, ou seja, em muitos casos, é ensinada longe de aplicações de construção dos conceitos, descontextualizada das práticas experimentais.

Com o advento das novas tecnologias e a presença delas nas atividades humanas, faz-se necessário que o docente se preocupe em despertar a atenção dos discentes para o conteúdo, havendo, assim, reflexões e mudanças nas atividades educativas. Soares (2008, p.18) aponta que os alunos aprendem mais quando são motivados; e o uso de novas ferramentas didáticas possibilita uma aprendizagem mais dinâmica.

Com o desejo de mudar este quadro, já há muito limitado, novas ferramentas e abordagens pedagógicas são empregadas como modificadores da realidade. Estes novos recursos buscam ativar a curiosidade e a motivação dos alunos, para dinamizar o ensino e diminuir a distância entre estes e o conhecimento. (Soares, 2008, p. 18).

O uso da tecnologia na educação faz parte de um processo natural do avanço da ciência. Valente (1999), apud Silva (2011, p.16), aponta que o computador é um instrumento valioso no processo de ensino e de aprendizagem e, portanto, cabe à escola utilizá-lo de forma coerente com uma proposta pedagógica atual e consistente.

Soares (2008, p.34) afirma que a utilização das tecnologias, em especial do computador, exige das instituições de ensino, e dos docentes, novas posturas frente ao processo de ensino e aprendizagem. Este modo de ensinar necessitará de um professor mediador do processo de interação da tecnologia. Deste modo, não basta utilizarmos os recursos tecnológicos como veículo educacional.

Para Soares (2008, p.76), é um grande desafio educar em tempos de tecnologias avançadas. O teórico afirma ainda que é de grande importância que as instituições de ensino trabalhem projetos que visem, num primeiro momento, a mudança de paradigmas e o surgimento de uma nova cultura sobre as estratégias de ensino (SOARES, 2008). Nesse sentido, o uso da tecnologia na educação faz parte de um processo natural do avanço da ciência, e, por esta razão, podem ser considerados novos instrumentos de trabalho que modificam as estruturas sociais, criando formas de ensinar e aprender. Por sua vez, os softwares educativos representam uma poderosa ferramenta para auxiliar professores e alunos na construção do saber. Segundo Ramalho (2013, p.2),

Ao utilizar computador juntamente com algum software educacional, os educadores obtêm resultados favoráveis ao ensino da Matemática, tendo em vista que é possível relacionar temas como modelagem matemática, trabalhos com calculadoras, resolução de problemas inerentes a funções, probabilidade, álgebra, geometria, exploração de gráficos entre outros. (Ramalho, 2013, p. 2).

Para Bona (2009, p.3), os softwares educativos podem auxiliar o aluno a adquirir e recapitular conceitos importantes. Este postula que o conjunto de situações, procedimentos e representações simbólicas oferecidas por esse recurso é amplo e atende muitos conteúdos, permitindo ao professor planejar de forma inovadora as atividades, possibilitando aos alunos apresentar novos significados a temas propostos (Bona, 2009).

Segundo Pereira (2010, p.25), as potencialidades de um software podem ser condensadas em quatro grandes categorias: 
1- Precisão e variedade na construção de objetos geométricos.

2- Exploração e descoberta.

3- Visualização ou representação mental de objetos geométricos.

4- Prova.

Com o software educativo surge também o termo geometria dinâmica, pois ocorre a passagem do estático para o movimento. Com as simulações, é possível realizar aplicações e investigações educacionais, o que implica a descoberta de conceitos e propriedades. Ramalho (2013, p.3) coloca que a exploração permite que seus conceitos sejam mais atrativos e acessíveis, pois, ao se mover um objeto na tela, pode-se observar suas propriedades, favorecendo o levantamento de conjecturas e hipóteses.

O GeoGebra é um software de Matemática Dinâmica que foi desenvolvido por Markus Horenwarter e Judith Preiner, originado para ser empregado no ensino e aprendizagem de Matemática nas escolas básicas e nível superior. É um aplicativo multiplataforma, podendo ser instalado em computadores com Windows, Linux ou Mac. Está disponível para download no link http://www.geogebra.org/cms/.

Segundo Bittencourt (2014), com o software GeoGebra, é possível trabalhar os conteúdos como: álgebra, geometria e cálculo. Este software possibilita construções com pontos, segmentos, retas, funções, vetores. Para Castro (2016), o software GeoGebra é capaz de lidar com variáveis para números, pontos, vetores, derivar e integrar funções, bem como oferecer comandos para se encontrar raízes e pontos extremos de uma função. Além disso, segundo Oliveira (2013, p. 32), "este software tem a vantagem de ser autoexplicativo, isto é, ao posicionarmos o mouse sobre algum item, é apresentada ao usuário a explicação da função daquela tecla".

No ensino da Matemática, muitas vezes, busca-se vincular o conteúdo ao contexto do aluno para facilitar a compreensão do conhecimento por parte dele, isto é, fazer analogias com situações vivenciadas pelo aluno e o conhecimento curricular estudado, para que, assim, o mesmo não seja tão somente abstrato, mas se torne concreto. (Giardinetto, 2015).

Sabemos que há muitos alunos que possuem dificuldades em visualizar determinadas propriedade geométricas, o que se torna possível com estes softwares, pois, neles, encontramos um recurso: o "arrastar". Esta é uma das principais características dos softwares citados. Tal comando abre novas possibilidades para o ensino de Geometria, baseado na exploração, simulações e verificações, o que possibilita que os conceitos básicos se tornem mais acessíveis para os alunos.

Chicon et al. (2011) salienta que, apenas com o recurso didático "quadro de giz", o professor apresenta dificuldades em desvelar o desenvolvimento de certos conceitos. Com o software GeoGebra, a aula transfigura-se em formato dinâmico, o aluno visualiza a Matemática em movimento e tem a possibilidade de conceber a sua essência. Neste caso, temos como fator favorável para aprendizagem a viabilidade da visualização gráfica, a qual é uma forma de representação que contribui fortemente para a compreensão e abstração dos conceitos matemáticos.

Em muitos casos, os discentes precisam de um instrumento para ajudar na compreensão dos conceitos, assim, tais softwares estabelecem relações entre os conhecimentos prévios e os novos. Neste processo de ensino, o professor deve agir como mediador, auxiliando os discentes em relação à utilização, de modo a formular hipóteses, despertar o interesse, direcionar para a visualização de conceitos matemáticos e incentivar o uso de recursos tecnológicos.

Deste modo, compreendeu-se que a utilização de softwares educativos coloca professor e aluno em uma posição dinâmica, de autonomia, para investigar propriedades, contribuindo, assim, com a ação cotidiana de um efetivo processo de ensino de tópicos de Geometria.

\section{Metodologia}

A proposta de investigação buscou estudar se a utilização do software GeoGebra e da pipa poderiam auxiliar 
metodologicamente durante as aulas de Matemática. Essa investigação está fundamentada na natureza qualitativa, pois ela permite compreender e interpretar as informações que foram selecionadas a partir da pesquisa (Flick, 2009). Essa proposta foi aplicada uma única vez, e buscou investigar as potencialidades do software no contexto da construção de pipa para aplicação prática, por representar interesses dos estudantes (Silva \& Menezes, 2005).

Para o bom andamento das atividades, os alunos foram organizados em equipes e seguiram as seguintes etapas:

a) Busca de informações: Os alunos realizaram consultas no laboratório de informática do colégio quanto à questão histórica, cuidados ao soltar pipas, curiosidades, imagens, voltados à construção da pipa e momento do voo.

b) Conteúdos matemáticos: Foram explicados e propostos exercícios envolvendo os conteúdos matemáticos a serem estudados. Nesta investigação, foram abordados os conteúdos matemáticos: posição relativa entre retas, vértice, ponto médio, retas perpendiculares, medida e soma de ângulos internos, cálculo de área e perímetro. Como revisão e proposição de conceitos, os alunos receberam uma folha impressa com a sequência de exercícios. Em um primeiro momento, esses exercícios foram resolvidos manualmente com auxílio de lápis, réguas e compasso e posteriormente resolvidos com o auxílio do GeoGebra.

c) Familiarização com o software GeoGebra: Os alunos foram levados até o laboratório de informática da escola, onde receberam orientações quanto à função do software, bem como as ferramentas necessárias para resolução de atividades envolvendo os conteúdos matemáticos dessa investigação. Os estudantes foram orientados oralmente, com o auxílio do projetor multimídia, a resolver a sequência de exercícios propostos em sala através das ferramentas existentes no software.

d) Análise comparativa dos conteúdos matemáticos estudados e a presença deles na pipa e respectiva construção: Nesse momento, os alunos foram questionados, de modo a terem a percepção de que os conceitos teóricos já estudados podem ser empregados para facilitar a confecção da pipa, o sucesso na hora do voo e a compra de materiais.

e) Construção e simulação da pipa no Software GeoGebra: Após a familiarização com o software, suas ferramentas e conceitos matemáticos, os alunos foram orientados oralmente passo-a-passo para a construção de uma pipa com o auxílio do software de Geometria dinâmica e seus recursos. Os educandos manipularam os vértices da pipa construída com o auxílio das ferramentas do GeoGebra e questionados com perguntas como: $\mathrm{O}$ que ocorre se aumentarmos e diminuirmos a figura? O que acontece com a pipa se movimentarmos apenas os vértices? E se movimentarmos o polígono, será que ela "voa"? Ela tem equilíbrio? Quando movimentamos os vértices, o que acontece com seus ângulos internos, com sua área e seu perímetro?

f) Oficina de pipas: Após todos os testes e simulações realizados no software GeoGebra, os alunos chegaram a um modelo "ideal". Os grupos construíram as pipas, utilizando-se de material concreto (varetas, folha de seda, etc), de acordo com o modelo e os resultados visualizados.

g) Análise dos resultados - O Momento do voo foi verificado através de uma atividade extraclasse. Cada grupo, no período vespertino, reuniu-se em um local apropriado para soltar as pipas e averiguar se as mesmas e todos os conceitos matemáticos foram aplicados de maneira correta. Os alunos registraram esse momento através de foto e vídeo com o auxílio do celular.

h) Avaliação da metodologia utilizada e conceitos ensinados - Para a verificação de dados foi proposto aos alunos uma avaliação dividida em duas etapas: na primeira, constavam três questões fechadas quanto a utilização e aceitação do software GeoGebra, sob as quais foram demonstrados os resultados na discussão do presente, e, na segunda etapa, questões referente os conteúdos matemáticos, tais como posição relativa entre retas, vértice, ponto médio, retas perpendiculares, medida e soma de ângulos internos, cálculo de área e perímetro.

Diante de toda a metodologia descrita, os conceitos matemáticos existentes na pipa, atrelados à tecnologia, foram expostos de forma lúdica. A aplicação junto aos alunos, mesmo que limitada pelo tempo escasso, permitiu a produção de dados, a compreensão de alguns limites e possibilidades do referido tema. 


\section{Resultados e Discussões}

Para a elaboração desta investigação, foram levadas em consideração as principais dificuldades observadas e identificadas no decorrer do ano letivo de uma turma de $8^{\circ}$ ano de um colégio estadual, localizado na periferia do município de Jacarezinho - PR. Tais atividades permitiram expor, ilustrar e demonstrar tópicos importantes dos conteúdos de geometria estudado, auxiliando metodologicamente o trabalho do professor e contribuindo para um ensino diferenciado para os participantes dessa pesquisa.

Está investigação foi dividida resumidamente, conforme Quadro1:

Quadro 1 - Resumo das etapas de implementação.

\begin{tabular}{|c|c|c|}
\hline Etapas & Quant. de Aulas & Local \\
\hline 1.Busca de informações & 2 aulas & Laboratório de Informática \\
\hline 2.Conteúdos matemáticos & 2 aulas & Sala de aula \\
\hline $\begin{array}{c}\text { 3.Utilização do software GeoGebra, análise } \\
\text { dos conteúdos matemáticos e a presença } \\
\text { dos mesmos na pipa. }\end{array}$ & 4 aulas & Se Informática \\
\hline 4.Oficina de pipas e análise dos resultados. & 2 aulas & Sala aula \\
\hline
\end{tabular}

Fonte: Autores (2021).

Conforme observado no Quadro 1, as aulas foram divididas em quatro etapas, sendo elas destinadas a investigações referente a pipa (duas aulas), estudo e explicação de conceitos matemáticos (duas aulas), a familiarização do software GeoGebra (quatro aulas) e construção de pipas (duas aulas). As mesmas foram ministradas na sala de aula e no laboratório de informática da escola.

$\mathrm{Na}$ etapa 1 (apresentada no quadro1), nominada busca de informações, os estudantes puderam investigar em sites as questões históricas e curiosidade da pipa, todos os cuidados e perigos envolvidos no momento de soltar pipas e imagens voltadas à construção da pipa e momento do voo. Os resultados obtidos nessa pesquisa foram mostrados através de apresentações, áudios e vídeos produzidos pelos grupos.

Na etapa 2 e etapa 3 foi explicado e proposto aos alunos a realização de alguns exercícios. Os mesmos foram realizados manualmente com o auxílio de lápis, réguas e compasso, e, posteriormente, resolvidos com o auxílio do GeoGebra no Laboratório de Informática.

Dentre os exercícios proposto destacamos a construção de retas paralelas, conforme visualizados nas Figuras 1 e Figura 2, construção de retas perpendiculares (figuras 3 e 4), soma dos ângulos internos de triângulos (Figura 5 e 6 ) e cálculos de áreas de losangos (Figuras 7 e 8).

Conforme Figuras 1 e 2, os alunos construíram de forma manual e utilizando o GeoGebra retas paralelas. 
Figura 1 - Retas paralelas construidas de forma manual.

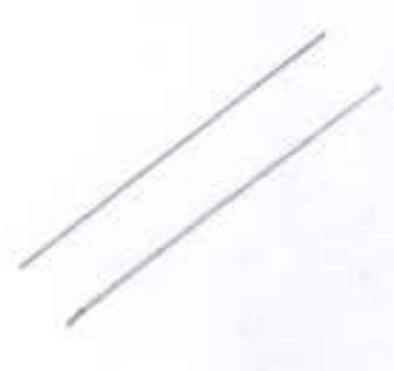

Fonte: Autores (2021).
Figura 2 - Retas paralelas construidas no GeoGebra.

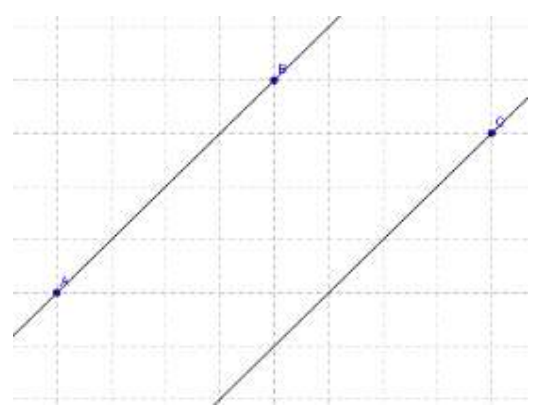

Fonte: Autores (2021).

O objetivo dessa primeira atividade, além da familiarização com régua, compasso (construção de forma manual) e o software GeoGebra, foi o entendimento dos conceitos matemáticos. Ou seja, os alunos puderam entender que duas retas são paralelas quando estão no mesmo sentido e não apresentam ponto em comum.

A segunda atividade proposta foi a construção de retas perpendiculares, conforme Figura 3 e 4.

Figura 3 - Construção de retas perpendiculares - forma manual

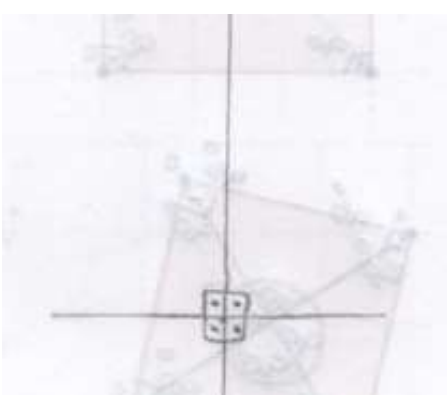

Fonte: Autores (2021).
Figura 4 - Constução de retas perpendiculares no GeoGebra

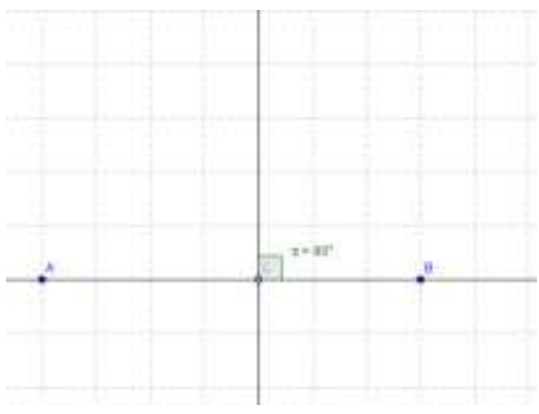

Fonte: Autores (2021).

A atividade teve como objetivo o entendimento dos conceitos de retas perpendiculares, ou seja, cruzam entre si num ponto comum formando um ângulo reto. Esta também teve o intuito do reconhecimento das retas na posição das varetas da pipa, que após pesquisas da etapa 1 (busca de informações), foram importantes para o sucesso do voo.

A terceira atividade foi referente a soma dos ângulos internos de um triângulo. As mesmas podem ser visualizadas nas Figuras 5 e 6. 
Figura 5 - Soma dos ângulos internos de um triângulo -

Figura 6 - Soma dos ângulos internos de um triângulo resolução manual. - resolução no GeoGebra.

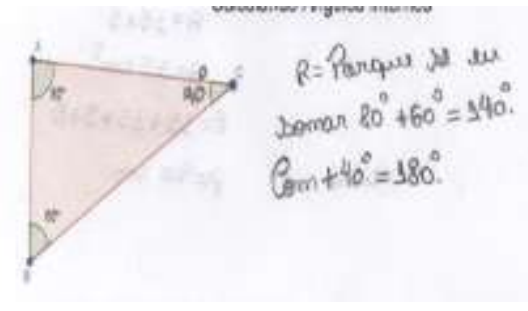

Fonte: Autores (2021).

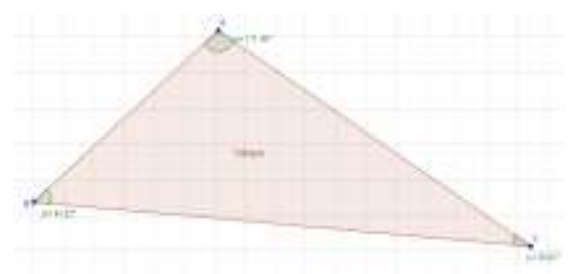

Fonte: Autores (2021).

A atividade teve como objetivo o entendimento que os triângulos são polígonos formados por três lados, e que a soma dos seus ângulos internos é sempre igual a $180^{\circ}$, independentemente do formato do triângulo, de seu tamanho ou de qualquer outra característica. Tal conceito foi visualizado de forma dinâmica no software GeoGebra e, nesse momento, os alunos podiam interagir e modificar esses objetos de maneira dinâmica. Foi possível a exploração, simulações e verificações, o que possibilitou que esse conceito básico fosse visualizado e comprovado, facilitando o entendimento dos alunos.

Foi proposto durante essas aulas o estudo de áreas e perímetros de figuras planas, como quadrado, retângulo, losangos, etc. As Figuras 7 e 8, demonstram os cálculos de área e perímetro de losangos.

Figura 7 - Área do Losango de forma manual.

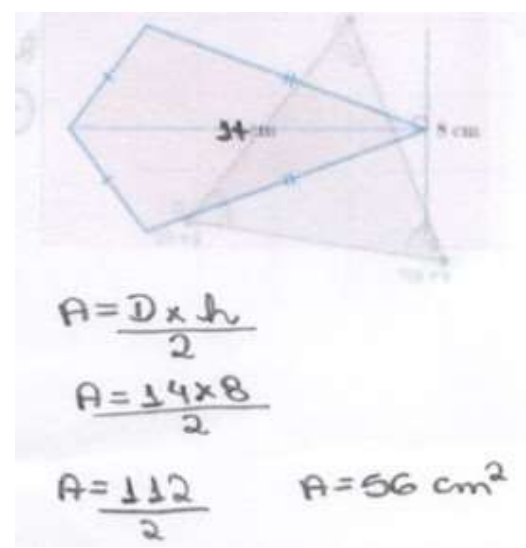

Fonte: Autores (2021).
Figura 8 - Área e perímetro do losango no GeoGebra.

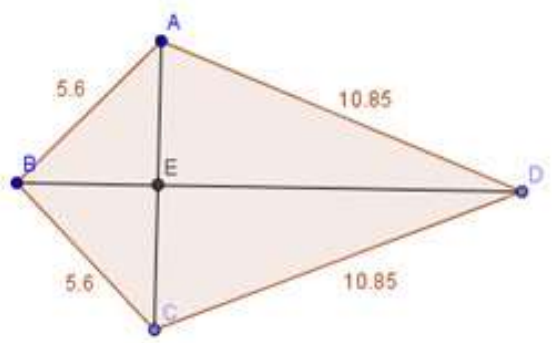

Area de $\mathrm{BADC}=56$

Perimetro de $B A D C=32.89$

Fonte: Autores (2021).

Essa atividade teve o como objetivo o entendimento e a importância do conceito de áreas. Foi nesse momento que os alunos entenderam tais propriedades na pipa, facilitando assim a compra e escolha dos materiais que, posteriormente, foram utilizados para a confecção das pipas.

Nessa etapa, os alunos se demonstram impressionados com a agilidade e facilidade do software e animados, pois, ao clicar em um botão, podiam construir retas perpendiculares, determinar ponto médio e visualizar instantaneamente respostas com a medida dos ângulos internos e externos, perímetro e área. Os estudantes questionaram a razão de eles não poderem arranjar todos os cálculos utilizando esse programa, ao invés de sempre resolvê-los manualmente. Alguns, inclusive, buscaram informações de como realizar download e instalação em computador pessoal. Sobre esse questionamento, foi informado aos alunos que o GeoGebra é um software livre, que poderiam realizar o download através do site http://www.geogebra.org/cms. 
Após a realização de exercícios básicos com as ferramentas do software GeoGebra e ajuda do professor, os alunos construíram uma pipa, com o objetivo de identificar as propriedades matemáticas existentes. Nessa fase, os alunos obtiveram imagens como as figuras 9 e 10.

Figura 9 - Pipa construída no GeoGebra - opção 1.

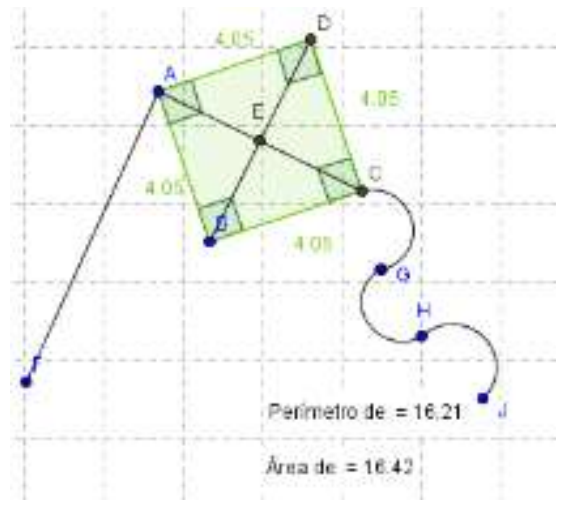

Fonte: Autores (2021).

Figura 10- Pipa construída no GeoGebra - opção 2.

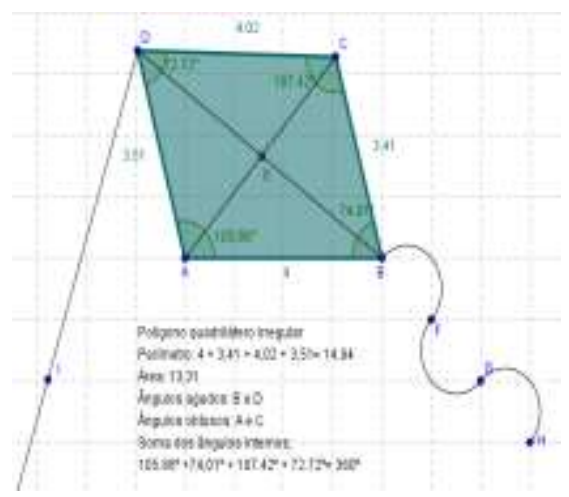

Fonte: Autores (2021).

Houve, nesse momento, uma reflexão de todos os conteúdos matemáticos estudados (posição relativa entre retas, vértice, ponto médio, retas perpendiculares, medida e soma de ângulos internos, cálculo de área e perímetro). Ao clicar nos vértices, foram realizadas simulações, sendo possível comprovar conceitos matemáticos que estavam presentes em uma brincadeira no seu cotidiano.

Com as simulações, os alunos chegaram a um modelo ideal, ou seja, uma pipa que, possivelmente, voaria e a quantidade de material necessário para a sua elaboração. Assim, os alunos souberam qual o tamanho das varetas, a quantidade de linha e folha de seda.

$\mathrm{Na}$ aula seguinte (etapa 4 - oficina de pipas), em sala de aula, os alunos foram convidados a confeccionar as pipas. $\mathrm{O}$ professor levou todo o material necessário para esse momento. Foi observado o material levado, os discentes escolherem a melhor vareta, mediram e fizeram desenhos nas folhas de seda. Os alunos, em equipe ou individualmente, eram questionados sobre os conceitos envolvidos em cada etapa para a confecção da pipa. O resultado dessa etapa é demonstrado nas Figuras 11 e 12. 
Figura 11 - Pipa confeccionada por um aluno.

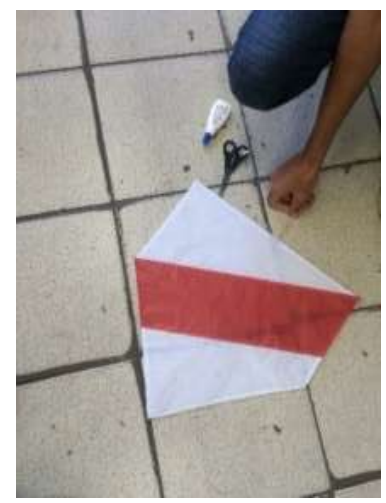

Fonte: Autores (2021).
Figura 12 - Pipa confeccionada por outros alunos.

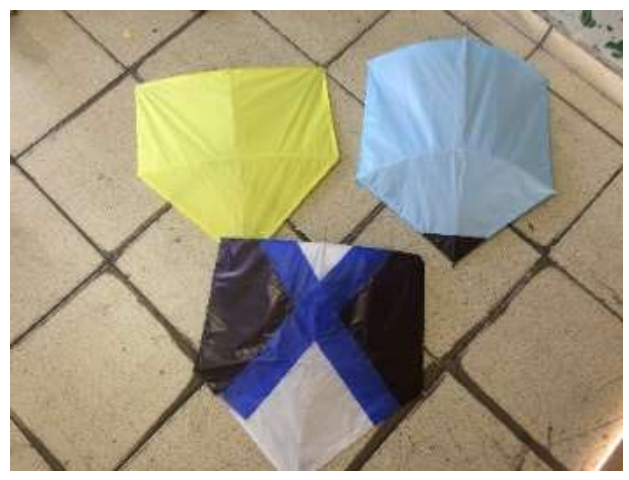

Fonte: Autores (2021).

Após a aula, os estudantes se reuniram em um lugar adequado, soltaram as pipas e verificaram se as propriedades matemáticas utilizadas foram suficientes para o sucesso do voo. Para registrar esse momento, foi solicitado aos alunos que tirassem fotos ou que fizessem vídeos. As figuras 13 e 14 registram esse momento.

Figura 13 - Momento do voo.

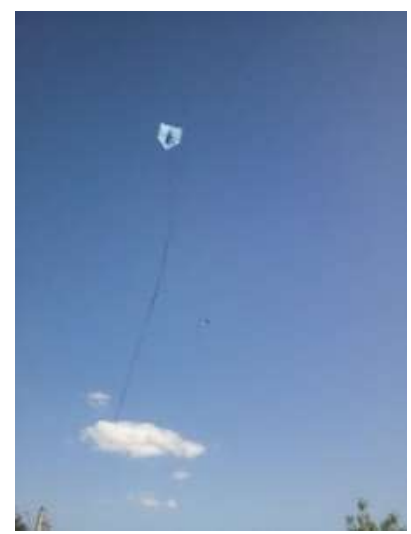

Fonte: Autores (2021).
Figura 14 - Momento do voo.

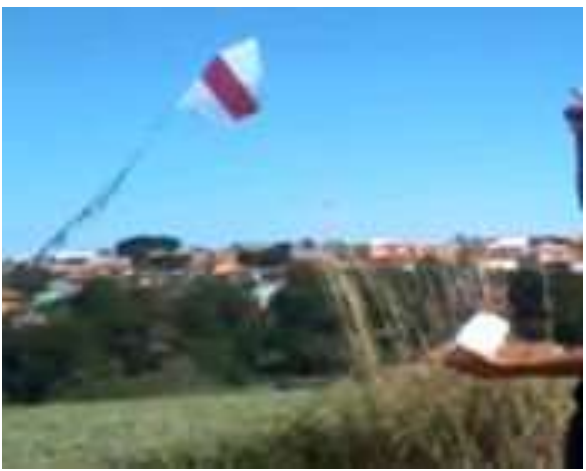

Fonte: Autores (2021).

Nas palavras dos alunos, as aulas passaram rapidamente. Percebeu-se, ao longo dessas atividades, o interesse, a curiosidade e o estímulo à aprendizagem. Houve atenção ao conteúdo apresentado, evidenciando-se facilidades e dificuldades apresentadas por cada grupo no decorrer do trabalho pedagógico.

Para verificar o entendimento dos conceitos matemáticos e a aceitação quanto ao uso dos softwares GeoGebra, foi realizada uma avaliação escrita. A mesma foi dividida em duas etapas:

1) Percepções dos alunos durante as aulas quanto a utilização e aceitação do software GeoGebra.

2) Questões matemáticas referente os conteúdos matemáticos estudados.

Demonstraremos, na sequência, os resultados obtidos de acordo com os questionamentos da etapa 1.

Os alunos foram questionados se já tinham estudado algum conteúdo matemático com um software de Geometria Dinâmica (GeoGebra) e, em resposta à consulta, obtivemos que $85 \%$ dos alunos não conheciam tais softwares matemáticos, ou seja, a sua utilização foi considerada uma novidade. 
Em um segundo questionamento, os alunos deveriam responder se acreditavam que, com a utilização do GeoGebra, os conceitos matemáticos referentes a ângulos, área, perímetro, etc, facilitaram a resolução de exercícios. Assim, $60 \%$ dos alunos afirmam que o GeoGebra e suas ferramentas facilitam na hora do entendimento de conteúdos matemáticos; $35 \%$ dos alunos mencionaram que esse software só poderia ser usado para calcular ângulos, áreas e perímetros e que seria necessário um número maior de aulas para compreender o software. Apenas 5\% dos alunos não acreditam que o GeoGebra pôde facilitar a compreensão de conceitos matemáticos.

Foi solicitado aos alunos que fizessem uma avaliação das aulas com a utilização do GeoGebra e da pipa. Constavam, nessa pergunta, as seguintes opções de resposta: fáceis, divertidas, chatas, difíceis, cansativas, legais, tradicionais, dinâmicas. Percebe-se, conforme apresentado no gráfico 1, que os adjetivos variaram, porém, todos apontam para uma aceitação da metodologia adotada:

Gráfico 1 - Percepções dos alunos das aulas - etapa 1 avaliação escrita.

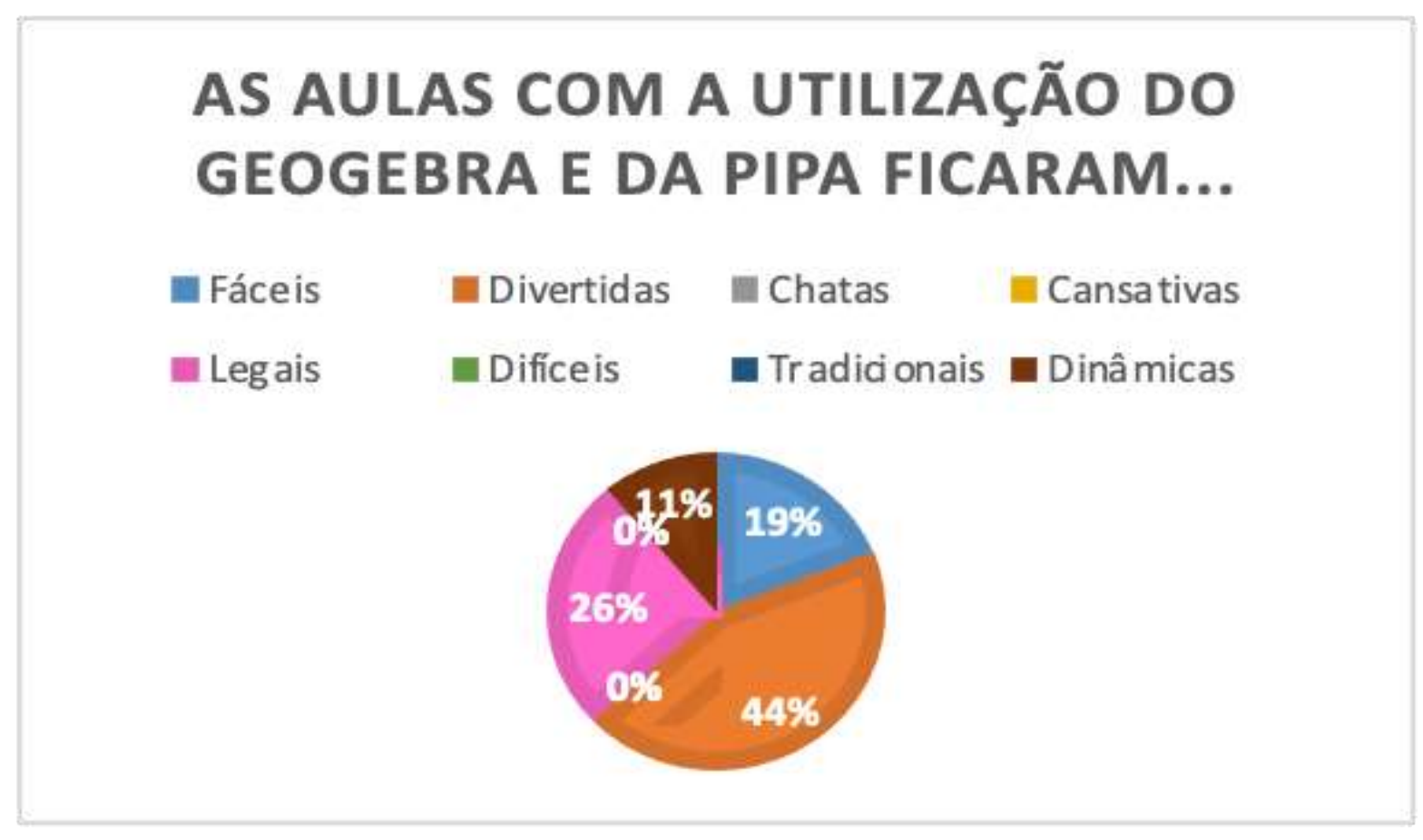

Fonte: Autores (2021).

Para a etapa 2, na avaliação escrita, constavam ainda 16 questões referentes aos conteúdos (posição relativa entre retas, vértice, ponto médio, retas perpendiculares, medida e soma de ângulos internos, cálculo de área e perímetro) estudados durante as aulas.

Os resultados obtidos foram demonstrados no Gráfico 2. Em seu eixo vertical, constam as quantidades de acertos (cor azul) ou erros (cor vermelha) de cada aluno. Os discentes foram identificados pelos números de 1 a 21, apresentados no eixo horizontal. Todos os alunos presentes nessa aula responderam ao questionário. 
Gráfico 2 - Quantidade de acertos e erros obtidos na Avaliação escrita - etapa 2.

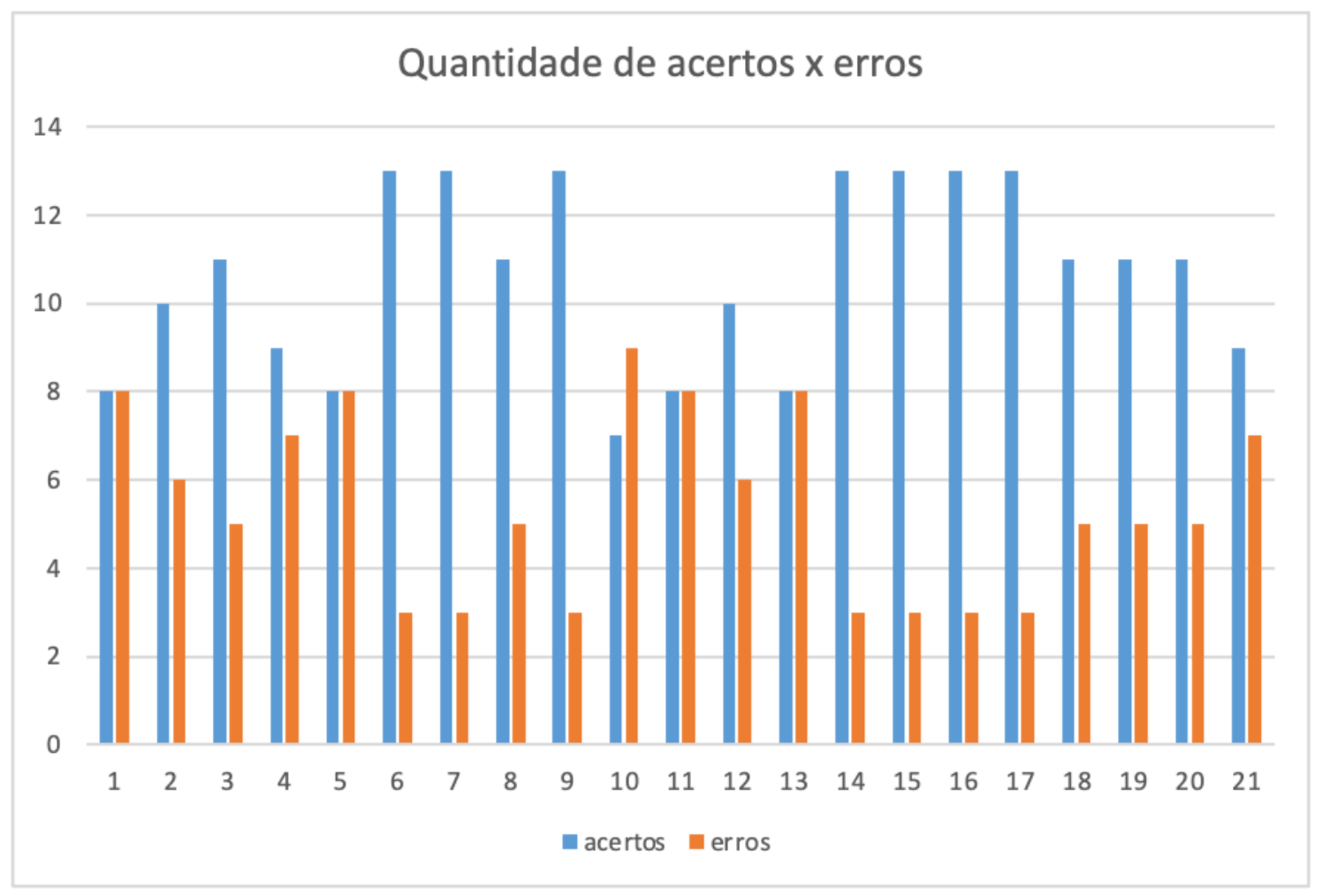

Fonte: Autores (2021).

Conforme consta no Gráfico 2, considerando que a atividade apresentava 16 exercícios, somente 1 aluno (indicado pelo número 10) obteve mais erros do que acertos. Quatro alunos (indicados pelos números 1,2,11 e 13) tiveram a mesma quantidade de erros e acertos. Os demais alunos apresentaram maior acerto. Observando ainda o Gráfico 2, nenhum aluno acertou todas as atividades, sendo necessário intervenção do professor com retomada de conteúdo. Quando questionados sobre as respostas, percebemos que houve um problema de interpretação textual nas respostas.

De acordo com Santana (2011, p.1), tem-se que, com o ensino da Geometria, surgem dificuldades na questão do desenvolvimento da abstração, pois, em sua maioria, as aulas são ministradas somente com livro didático, lápis, borracha, papel, régua, esquadro e compasso, os quais são ótimos recursos educacionais, porém, não são os únicos elementos usados para tal fim. Nesse contexto, os softwares educativos, em especial o GeoGebra, tornaram-se ferramentas utilizadas como facilitadoras no processo de ensino e aprendizagem, pois caracterizam-se pela mobilidade e flexibilidade das figuras construídas, que podem ser movidas e alteradas facilmente, propiciando a compreensão de conceitos geométricos importantes, sendo o professor somente o mediador do conhecimento.

Além dos resultados numéricos apresentados, houve envolvimento e uma intensa participação de todos os participantes. Foi demonstrado um grande interesse em estudar conceitos matemáticos existentes na pipa utilizando-se o GeoGebra. Os dados analisados possibilitaram identificar resultados positivos em relação ao ensino dos conteúdos: posição relativa entre retas, conceito de vértices, ponto médio, medidas e soma de ângulos internos e cálculos de área e perímetro. A dinamicidade e as potencialidades oferecidas pelo GeoGebra contribuíram para os processos de ensino dos conteúdos acima mencionados, uma vez que os alunos puderam construir conceitos, realizar simulações e manipular as figuras na tela do computador. Tais demonstrações, permitem uma maior compreensão dos conteúdos e propriedades matemáticas, tornando a aula mais atrativa e capaz de sanar algumas dificuldades que somente o uso da metodologia tradicional não resolveria. 


\section{Considerações Finais}

Ao vivenciar a realidade dessa turma, teve-se uma árdua tarefa, pois os alunos são dispersos em sua maioria, existindo casos de indisciplina e dificuldades de compreensão dos conteúdos.

Com a utilização do software GeoGebra e da pipa, obteve-se bons resultados e a participação e a disciplina prevaleceram nessas aulas, haja visto que os discentes se mostraram satisfeitos com a metodologia adotada.

Todos os alunos resolveram as atividades propostas com grande expectativa de aprenderem Matemática de uma forma pedagógica diferenciada. As dificuldades encontradas foram trabalhadas em sala de aula ou no laboratório de informática, através de explicações, simulações, exemplos e exercícios. Sempre que necessário, foram realizadas intervenções para que os discentes tivessem um maior entendimento sobre o conteúdo proposto. Observou-se aprovação para a inserção de uma maneira pedagógica diferenciada da usual, sendo que tais recursos contribuíram para a compreensão do conteúdo trabalhado em sala de aula, levando-os à visualização e entendimento das situações propostas.

Para a obtenção desses resultados, as aulas foram planejadas, com pesquisas, objetivos claros e definidos. Todo material foi elaborado considerando as características dessa turma, e o software GeoGebra facilitou, inovou e enriqueceu as aulas de Matemática, promovendo uma melhoria no ensino e favorecendo a integração entre os conteúdos e as novas tecnologias.

Os dados permitem afirmar que é possível utilizar o software GeoGebra, o mesmo não resolverá todos os problemas de aprendizagem para compreensão de conceitos e de aplicação dos tópicos de geometria, mas poderá servir como uma ferramenta para facilitar o aprendizado, a comunicação, a relação entre professor/aluno e minimizar as dúvidas.

Contudo, ainda há um grande caminho a percorrer quando pensamos na inserção das tecnologias por meio dos softwares educativos para o desenvolvimento de competências e habilidades. Para que essas aulas ocorram de maneira efetiva é necessário planejamento, havendo sempre um equilíbrio na utilização desses recursos, sendo necessário que o docente atue como mediador do processo de ensino-aprendizagem.

Desse modo, fica evidente a importância de se introduzir os softwares nesse processo, sendo necessário o aprimoramento dos recursos tecnológicos nas instituições educacionais, possibilitando o maior acesso a tais ferramentas. Vale ainda destacar a importância da qualificação contínua dos profissionais para atuarem de forma efetiva, com foco na especialização da ação docente. Por fim, os softwares podem ser utilizados como incentivadores do processo educativo nas aulas de Matemática, pois despertam um maior interesse nos alunos, tornando-os críticos, reflexivos e contribuindo para a formação de conhecimentos, de acordo com as exigências do mundo em que vivem.

Considerando os resultados obtidos foi possível verificar a necessidade de estudos suplementares e o desenvolvimento de outras propostas similares, haja visto que as investigações dessa natureza podem estimular um ensino dos conteúdos escolares por meio de metodologias alternativas. O ensino da matemática pode ser pensado não apenas como um componente curricular, mas como um conjunto de saberes presentes no cotidiano dos estudantes

\section{Referências}

Bona, B. (2009). Análise de Softwares Educativos para o Ensino de Matemática nos Anos Iniciais do Ensino Fundamental. http://www.if.ufrgs.br/een ci/arti gos /Artigo_ID71/v4_n1_a2009.pdf

Brasil, (1999). Ministério da Educação, Secretaria de Educação Média e Tecnológica. Parâmetros Curriculares Nacionais: Matemática - $1^{o}$ e $2^{o}$ ciclos de Ensino Fundamental.

Brasil. (2016). Ministério da Educação. Base Nacional Comum Curricular. Ministério da Educação

Brasil. (1996). Lei de Diretrizes e Bases da Educação Nacional. http://portal.mec.gov.br/seesp/arquivos/pdf/lei9394_ldbn1.pdf

Bittencourt, P. M. (2014). Utilização do Geogebra na construção de instrumentos. (Dissertação de Mestrado). Instituto de Matemática Pura e Aplicada. 
Research, Society and Development, v. 10, n. 11, e515101119776, 2021

(CC BY 4.0) | ISSN 2525-3409 | DOI: http://dx.doi.org/10.33448/rsd-v10i11.19776

Castro, Carlos E. B. (2016). O Estudo de algumas funçães elementares com o Geogebra. (Dissertação de Mestrado). Universidade Federal de Juiz de Fora, Juiz de Fora, MG, Brasil.

Chicon, et al. (2011). Geogebra e o Estudo da Função Quadrática. https://home.unicruz.edu.br/seminario/anais/anais-2011/agrarias/GEOGEB RA\%20E\%2 0O\%20ESTUDO \%20DA\%20FUN\%C3\%83\%E2\%80\%A1\%C3\%83\%C6\%92O\%20QUADR\%C3\%83\%C2\%81TICA.pdf

D’ambrósio, U. (2013). Etnomatemática: Elo entre as tradições e a modernidade. Autêntica. http://www.educacao.rs.gov.br/pse/html/proj_provincia.jsp

Ecco, O. C. (2016). Compreensão de conceitos de geometria a partir da construção de sólidos geométricos em uma turma de EJA de Ensino Médio. (Dissertação de Mestrado). Universidade Federal da Santa Maria, Santa Maria, RS, Brasil.

Flick, U. (2009). Pesquisa qualitativa: por que e como fazê-la. In: Introdução à pesquisa qualitativa. (3a ed). Artmed.

GeoGebra Privacy Policy. (2020). O que é o geogebra. http://www.geogebra.org/cms/pt_BR/info

Giardinetto, J. R. B. (2015). Abstrato e o Concreto no Ensino da Matemática: Algumas Reflexões. Revista Bolema, (12), 45-57.

Hargreaves, A. (1998). Os professores em tempos de mudança. McGraw-Hill.

Lorenzato, S. (1995). “Por que ensinar Geometria?”. Revista Sociedade Brasileira de Educação Matemática, (5), 33-46.

Miranda, D. F. \& Blaudares, J.B. (2007). Informatização no ensino de matemática: investindo no ambiente de aprendizagem. Zetetiké, 15-27. https://doi.org/1 0.203 96/zet.v15i27.8647017

Oliva, W.M. (1981). Geometria não euclidiana. Revista do professor de matemática. (2), 28-31.

Oliveira, H. (2013). Descobrindo as Razões Trigonométricas no Triângulo Retângulo. (Dissertação de Mestrado). Universidade Federal de São Carlos, São Carlos, SP, Brasil.

Pereira, M. T.(2010). Proposta de Atividades para a Construção do Conceito de Semelhança de Triângulos Usando o Software de Geometria Dinâmica Régua e Compasso. (Dissertação de Mestrado). Universidade Severino Sombra, Vassouras, RJ, Brasil.

Ramalho, L. V.(2013). O uso do Geogebra no Ensino de Matemática. http://www.sbemgo.com.br/anais\%20engem_2013/Relatos \%20de\%20E xperi\%C3\%A Ancia/re_03353420193.PDF

Santana, A. B.(2009). Interdisciplinaridade e contextualização. http://joelbarrosmatematica.blogspot.com/2009/11/interdisciplinaridade-e.html

Santana, A. B. (2009). Interdisciplinaridade e contextualização. http://joelbarrosmatematica.blogspot.com/2009/11/interdisciplinaridade-e.html

Silva, J. J. (2011). O Software Régua e Compasso como Recurso Metodológico para o Ensino de Geometria Dinâmica. (Dissertação de Mestrado). Universidade Estadual da Paraíba, Campina Grande, PB, Brasil.

Silva, E. L.; \& Menezes, E. M. (2005). Metodologia da Pesquisa e Elaboração de Dissertação. (4a ed). Portal.

Soares, L. A. (2008). Aprendizagem Significativa na Educação Matemática: uma proposta para a aprendizagem de geometria básica. (Dissertação de Mestrado). Universidade Federal da Paraíba, João Pessoa, PB, Brasil. 